\title{
Testing the KAPS Model of Reading Comprehension in a Turkish Elementary School Context from Low Socioeconomic Background
}

\author{
Kasim Yildirim ${ }^{1, * \mathbb{D}}$, Fatih Cetin Cetinkaya ${ }^{2}$, Seyit Ates ${ }^{3}$, Dudu Kaya ${ }^{4}$ and Timothy Rasinski ${ }^{5}$ \\ Department of Elementary Education, Mugla Sitki Kocman University, 48000 Mentese/Mugla, Turkey \\ Department of Elementary Education, Duzce University, 81620 Duzce, Turkey; cetincetinkaya@duzce.edu.tr \\ Department of Elementary Education, Gazi University, 06500 Yenimahalle/Ankara, Turkey; \\ seyitates@gmail.com \\ 4 Department of Elementary Education, Pamukkale University, 20160 Pamukkale, Turkey; \\ dkaya13@pau.edu.tr \\ 5 Department of Literacy Education, Kent State University, Kent, OH 44242, USA; trasinsk@kent.edu \\ * Correspondence: kasimyildirim@mu.edu.tr; Tel.: +90-252-211-5022
}

Received: 23 February 2020; Accepted: 23 March 2020; Published: 27 March 2020

\begin{abstract}
This correlational study aimed to explore the relations of background knowledge, automaticity (rate), prosody, and strategy use with reading comprehension (KAPS model of reading comprehension) in the written Turkish language context with 207 fourth grade students. Successful comprehension requires readers to make meaning out of what they read. Our KAPS model of reading comprehension hypothesizes relations of background knowledge, fluency components (rate and prosody), and strategy use with reading comprehension components (literal and deep) in the Turkish language and addresses the direct effects of these predictors on the reading comprehension of fourth grade students. The results showed that, whereas fluency and strategy use made statistically significant contributions to reading comprehension, background knowledge did not. Based on the results, the study affirms the importance of automaticity in word recognition, prosody, and comprehension strategies in contributing to reading comprehension in Turkish and, as such, should be given priority for literacy instruction in Turkish.
\end{abstract}

Keywords: reading comprehension; KAPS model; comprehension strategy use; reading fluency; background knowledge

\section{Introduction}

Reading comprehension, in any language, is the cognitive process of simultaneously extracting and constructing meaning through interaction and involvement with written texts [1-3]. Reading comprehension is often viewed as a binary capability involving literal and inferential comprehension outcomes. While literal comprehension is related to readers retrieving explicit information directly from a text $[4,5]$, inferential comprehension involves the readers' consideration of content beyond the text and requires readers to integrate their perspectives with that of the text author. As such, inferential comprehension is theorized to be the result of analyzing and synthesizing knowledge from different sources [5-7].

Beyond the two levels of comprehension, reading comprehension is a complex process that is affected by a variety of cognitive factors, such as reading fluency, purposes for reading, usage of comprehension strategies, vocabulary knowledge, and background knowledge. Additional contributors to comprehension include readers' knowledge of printed language structure and language conventions through which information is conveyed [1,8-11]. 
Fluency is the ability to read text accurately, automatically (at the speed of oral language), and with prosody. Fluency has been described as the bridge between word recognition and comprehension in that fluency, or automatic reading, frees up cognitive resources from word decoding to processing meaning [12] Readers who attain automaticity in decoding, have sufficient prior knowledge, and are proficient in other contributing processes of comprehension are able to make meaning from the text with relative ease [13]. Scientific studies have demonstrated consistent and positive relationships between reading fluency and comprehension [14-19].

The awareness of the importance of prior knowledge for reading comprehension is critical. Before synthesizing and analyzing new information, previous experiences or background knowledge need to be connected to and integrated with the new information in a text. In every new meeting with the text, the reader brings her/his total previous experiences to make meaning from the text [20]. Research has shown that comprehension is enhanced when readers activate and use prior knowledge to make connections with the text when reading [21,22].

Skilled readers also employ a variety of comprehension strategies and competencies to comprehend text [23]. Reading comprehension-related strategies include activating background knowledge, summarizing, identifying main idea, awareness of text structure, predicting, and self-questioning [24]. These reading competencies support the reader in gaining and constructing meaning from text [8]. Previous research in reading English has focused on the competencies and strategies employed by proficient readers when reading. Mariotti, for example, [10] articulates that strong vocabulary, use of strategies, reading fluency, and prior knowledge are underlying factors of proficient reading comprehension. When readers activate their prior knowledge and make connections to prior knowledge, and with the use strategies, they can comprehend better what they read [25,26].

The role and importance of comprehension-related strategies in Turkish, and with the students manifesting reading difficulties, however, are less well understood [27-32].

Previous research in Turkey has explored the relationship between prior knowledge and other comprehension strategies and competencies. Akyel and Ercetin [33] investigated the relationship between the sufficiency of prior knowledge and use of comprehension strategies such as questioning, creating mental images, summarizing, and making predictions. Greater prior knowledge resulted in more use of comprehension strategies. Other research has shown a strong relationship between vocabulary and reading fluency [34]. Additionally, Beydogan [35] noted positive and significant relationships between strategy use and reading fluency. In another study, Ates and Yildirim [34] investigated the extent to which practices related to reading instruction and strategy are used in classroom settings. The findings revealed that elementary classroom teachers do not employ strategies to improve students' reading comprehension and do not teach strategies to students explicitly.

In this study we attempted to expand our understanding of the relationship between the various comprehension factors and reading comprehension for Turkish elementary students. It focused on the relationships and interactions between background knowledge $(\mathrm{K})$, reading fluency (both automaticity (A) in word recognition and prosody (P)), comprehension strategy (S) employment, and reading comprehension. We hypothesize that these various factors together contribute to students' reading comprehension in a theoretical model we termed KAPS.

In the current study, we attempted to test the KAPS model in a Turkish language context. There were two main research questions, as follows:

1. Does the KAPS model adequately represent reading in the Turkish language?

2. What components of the KAPS model show relationships with reading comprehension?

\section{Methods}

\subsection{Research Design}

This research is a correlational study where we sought to understand what kind of relations reading fluency, background knowledge, and strategy use have with reading comprehension. Through 
this design, we aimed to clarify the hypothesized the KAPS model of reading comprehension in a Turkish. Therefore, structural equation modeling (SEM) was employed for the analysis. The reason why we used SEM is that structural equation modeling, which is a statistical technique, is used to measure underlying hypothetical constructs and their interrelationships.

\subsection{Participants}

The purpose of the study was to explore the relationships of background knowledge, reading fluency, and strategy use with reading comprehension in Turkish elementary-grade students. A total of 207 fourth graders from five different classes in the same school were enrolled in the study. The research took place in fall and spring semesters, 2016, in Turkey's Denizli province. The participants were willing and available to take part and informed consent letters were obtained from all of the participants and all parents or guardians. The subjects were relatively homogenous, of middle socioeconomic (SES) status, and ranged in age from 9 through 10 years. Seventy-eight girls and 119 boys who participated in the study were not identified as learning disabled and their reading development was felt to be within grade level expectations according to their classroom teachers and the school counselor. All of the students were considered typically developing readers by their teachers.

\subsection{Materials and Methods}

\subsubsection{Texts}

The students read an expository text that consisted of 338 words. Assessments of literal and deep comprehension, background knowledge, and fluency (both automaticity and prosody) were based on students' reading of this text. The text, which was about cartoons, was obtained from a grade appropriate Turkish language arts course textbook. The text explained the nature of cartoons, their historical development, types of cartoons, and the role of cartoons in communication. The other short passages for assessing strategy use were obtained from the same fourth grade textbook and were either reorganized or shortened for the reading strategies.

\subsubsection{Reading Fluency}

Reading fluency, including word recognition automaticity and prosody, was assessed using the expository text. Automaticity was determined by calculating the number of words read correctly in the initial 60 seconds of oral reading. Prosody was assessed qualitatively by a researcher who listened to each student read the grade-level passage and rated the prosodic quality of the oral reading using a rubric that describes levels of competency on various elements of prosody (expression/volume, phrasing, smoothness, and pace). The rubric was developed by Rasinski [36] and adapted by Yildiz, Yildirim, Ates, and Cetinkaya [37] for use with Turkish students. Prior research using the rubric with English readers has demonstrated the rubric to be a reliable and valid measure of prosody [38,39]. The Turkish adaptation of the scale included the same four main dimensions in previous studies [36]. Students' scores for the full prosody assessment ranged from a minimum of 4 and a maximum of 16 .

\subsubsection{Background Knowledge}

The researchers developed a 10-item, multiple-choice test to assess the students' background knowledge about cartoons, the content in the main text. The researchers examined the text to identify content (knowledge) that was judged to be essential for correctly answering the questions. Distractors in the background knowledge test included either facts that were presented in the text or events that were judged to be familiar from participants' everyday experiences but not consistent with the information presented in the text. The test-retest reliability of the prior knowledge measure was computed, with 3 weeks between the test and the retest. A The reliability estimate was determined to be (Pearson r) 0.81 (see Appendix A). 


\subsubsection{Reading Comprehension Strategies}

Strategy use was determined using a 12-item, researcher-developed measure that was based on work by Kozminsky and Kozminsky [40] and was also similar to the measures employed in previous research [41,42]. Short passages, appropriate for fourth grade, were identified from fourth grade Turkish language arts textbooks. After reading each passage, the students answered two multiple-choice items that required the use of various reading comprehension strategies. For example, for the strategy of summarizing, students read a passage and were presented with four possible summary sentences. Their task was to choose the best summary of the passage. Based on the findings from previous research relevant to strategy instruction, we identified and assessed six strategies: activating background knowledge, summarizing, identifying main idea, awareness of text structure, predicting, and self-questioning (see Appendix B).

\subsubsection{Reading Comprehension}

Following previous research [43], we developed a sentence verification task (SVT) to measure the students' literal comprehension of the main text (Cronbach's Alpha $=0.71$ ). The SVT was developed by generating four types of test items from sentences in the text/s: (a) originals, which were copies of sentences that appeared in the text/s; (b) paraphrases, which were constructed by changing as many words as possible in original sentences without altering the essential meaning; (c) meaning changes, which were constructed by changing one or two words in original sentences so that the meaning of the sentences was altered; and (d) distractors, which were syntactically similar and thematically related to the original sentences but were not consistent with the meaning to the originals. The test consisted of 16 items (four originals, four paraphrases, four meaning changes, and four distractors) that the participants were asked to mark "yes" for items that had the same meaning as text sentences (originals or paraphrases) or "no" for those that had a different meaning (meaning changes and distractors).

Again, following Royer et al. [43] and Strømsø, Bråten, and Samuelstuen [44], we constructed an inference verification task (IVT) to measure the students' deeper or inferential, understanding of the same text (Cronbach's Alpha $=0.67$ ). This test consisted of 16 items, 8 of which were near inference items and 8 of which were far inference items. The near inference items were constructed by combining information in the text to form either a valid or invalid inference. The far inference items were constructed by combining an item of information from the text with information that the student would likely have about the topic in order to create valid or invalid inference. The students were instructed to mark "yes" for the items that could be inferred from material presented in the text, and "no" for those that could not be inferred from material presented in the text (see Appendix C).

\subsection{Procedure}

Prior to the study, the main text, short passages and accompanying questions were reviewed by experts in reading education from a public university in Turkey. All reviewers had Ph.D. degrees in elementary school education. The experts reviewed the extent to which the texts adequately corresponded to reading domain objectives of the fourth grade Turkish language arts curriculum and the extent to which the questions adequately measured comprehension of the texts. The experts also verified that each comprehension question was appropriate given developmental standards and the students' reading levels.

Students initially completed the multiple-choice background knowledge test. Next, they were asked to read the grade-appropriate expository text on cartoons and complete the SVT and IVT tests. Students were tested individually and asked to orally read the passage corresponding to their grade level placement. The students were asked to read the text in their best or most expressive (prosodic) voice and were told that they would be questioned about what they had read following their reading. During each student's oral reading, the researcher administering the test marked any uncorrected word recognition errors made by the student as well as marking the text position of the student at the end of 
60 seconds in order to determine reading rate, a measure of word recognition automaticity. Prosody, or expressive reading, the second element of fluency, was measured by independent evaluators listening to the student reading and then rating the prosodic quality of the oral reading using the Turkish adaptation of the multi-dimensional fluency rubric [45].

\section{Results}

The data obtained from the students' readings included measures of literal and inferential comprehension, word recognition automaticity (words read correctly per minute), prosody (qualitative rating of expressiveness using the multi-dimensional fluency scale), background knowledge, and strategy emloyment. Means and standard deviations for the six variables are presented in Table 1.

Table 1. Mean and standard deviations for the variables including comprehension and fluency components, strategy, and background knowledge.

\begin{tabular}{clccc}
\hline Grade & & N & M & SD \\
\hline \multirow{4}{*}{4} & Literal Comprehension & 207 & 10.22 & 2.03 \\
& Deep Comprehension & 207 & 10.13 & 2.06 \\
& Prosody & 207 & 12.50 & 2.94 \\
& Rate & 207 & 82.10 & 18.39 \\
& Strategy & 207 & 6.70 & 2.50 \\
& Background Knowledge & 207 & 3.97 & 1.55 \\
\hline
\end{tabular}

The relationship between the comprehension related factors and comprehension itself, was determined by calculating correlations between variables. The correlations are presented in Table 2; all correlations were found to be statistically significant and substantive.

Table 2. Correlations of fluency components, strategy, and background knowledge with comprehension components.

\begin{tabular}{cccc}
\hline Grade & & Literal Comprehension & Deep Comprehension \\
\hline & Rate & $0.36^{* *}$ & $0.39^{* *}$ \\
4 & Prosody & $0.40^{* *}$ & $0.33^{* *}$ \\
& Background & $0.18^{* *}$ & $0.21^{* *}$ \\
& Strategy & $0.34^{* *}$ & $0.31^{* *}$ \\
\hline
\end{tabular}

Note: ${ }^{* *} p<0.01$.

Given the positive and significant correlations among the variables in Table 2, we ran a path analysis using AMOS and Mplus statistical modeling programs. By this analysis, we aimed to determine the relations among the variables in an integrated model of reading comprehension. Those results are presented in the path diagram in Figure 1.

In the path analysis model, fluency, comprehension strategies, and background knowledge were used to predict reading comprehension. The path analysis results revealed that RMSEA, SRMR, TLI, and CFI values were within expected ranges. The fit of the data, then, to the proposed path model was considered good. For the full sample, the model yielded good fit indices. When reviewing overall fit summary indices in the model, the $\chi 2$ test yielded a value of 5.752, which was evaluated with 5 degrees of freedom, and had a corresponding $p$-value of 0.331 . The $\chi 2 / d f$ was 1.150 . Additionally, the RMSA was 0.027. The TLI was 0.99 and CFI was 0.99. Moreover, SRMR was 0.0132. These fit measures suggest that all of the indices expressed in the path analysis were a good fit to the data [46,47]. In the model, fluency and comprehension strategies made statistically significant contributions to the prediction of reading comprehension ( $\beta=0.46, p<0.001$ and $\beta=0.27, p<0.01$, respectively). Background knowledge, however, did not make a statistically significant contribution to the prediction of reading comprehension ( $\beta=0.13, p>0.05)$. Overall, this model explained $45 \%$ of the variance in 
reading comprehension. Having a relatively high R-squared value in these predictions indicates that this model works well in the Turkish language context.

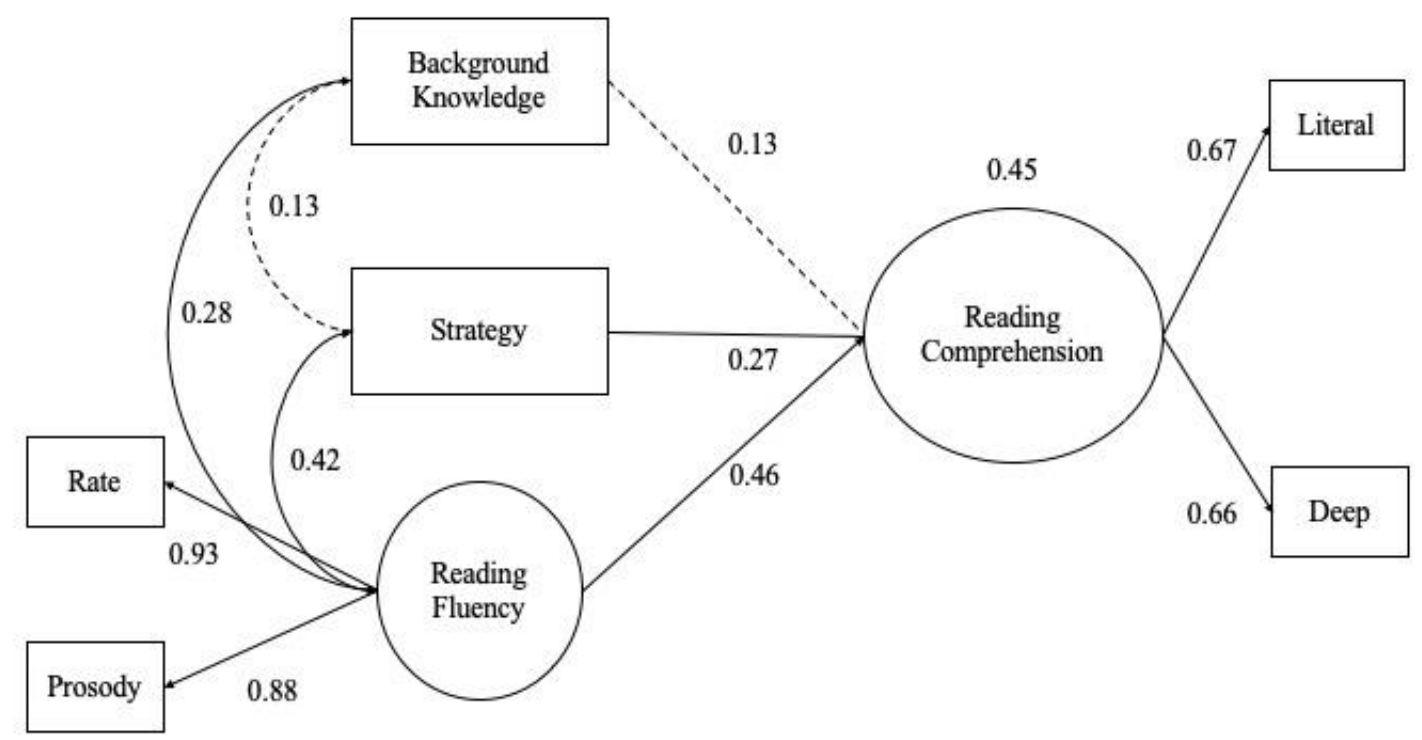

Figure 1. The relations of strategy use, reading fluency, and background knowledge with reading comprehension. The single-headed arrows show standardized regression coefficients and direct effects in the path model. Double-headed arrows represent correlations (covariance). Dotted arrows show insignificant coefficients in the path model. ${ }^{* * *} p<0.001$.

\section{Discussion}

In the current study, we aimed to explore the validity of the KAPS model in the Turkish language context with Turkish elementary students by determining the direct relationships between fluency, background knowledge, and strategy usage as they contribute to comprehension. All contributors to comprehension, except for background knowledge, were found to be components of the model for reading comprehension.

A successful comprehension process requires the reader to make meaning. Previous research has shown that comprehension requires readers to employ prior knowledge and integrate it into text processing [20]. Additionally, comprehension occurs when readers connect their prior knowledge to the text, make connections between different parts of the text, and make connections between known and unknown information [11]. While previous research has shown that there are profound positive relations between prior knowledge and reading comprehension [21,22,26], the results suggest that, in a more complex model of comprehension, there was no significant relationship between reading background knowledge and reading comprehension. Students' ackground did not contribute significantly to the prediction of reading comprehension in the path analysis model. This result was not consistent with the previous research findings. In as much as previous research has verified the importance of background knowledge, the lack of a significant contribution of this variable in the current study may have been due to the use of an assessment of background knowledge that insufficiently assessed students' knowledge. Future research of models of reading in Turkish need to consider more robust measures of students' background knowledge.

The other result of the present study suggests a strong relation between reading strategy use, fluency, and comprehension. Fluent and proficient readers know how to and when to use reading comprehension strategies when they read. In other words, fluent readers are able to effectively use reading strategies during reading. This enables them to monitor reading comprehension processes [48,49]. The students' scores of strategy use made statistically significant and substantial contributions to reading compression. This result was consistent with the previous research $[10,31,50]$. Mariotti $[10]$ has found that vocabulary 
and strategy use were significant components of reading comprehension. Moreover, Seipel et al. [31] reported that proficient readers are better in strategy use compared to poor readers. Additionally, Reed and Lynn [44] found that using comprehension strategies such as making inferences from the text to be read had significant effects on reading comprehension.

The results of this study affirm the significance of fluency (including both automaticity in word recognition and prosody) as a significant variable in proficient reading and reading comprehension [9,18,51-55] in Turkish fourth grade students. As such, continued instruction in reading fluency, automaticity, and prosody, for Turkish students beyond third grade is warranted. Additionally, instruction in the application of specific comprehension strategies can also be recommended. Comprehension is not a passive task, and the use of comprehension strategies ensures that readers will actively monitor and process meaning as they read. Thus, comprehension strategies, especially the ones tested in the present study, and reading fluency (automaticity and prosody) need to be given priority for literacy instruction for Turkish elementary students, at least through Grade 4, and perhaps beyond for struggling readers. In conclusion, while the current study could not validate the complete hypothesized KAPS model of reading comprehension in Turkish language, it adds to the accumulating evidence of the importance of reading fluency and comprehension strategies for proficient reading, especially among upper elementary school students.

Author Contributions: Conceptualization, K.Y. and T.R.; methodology, K.Y. and D.K.; software, K.Y.; validation, S.Y., F.C.C., and T.R.; formal analysis, K.Y. and D.K.; investigation, K.Y. and D.K.; resources, K.Y. and D.K.; data curation, K.Y., D.K., S.A., and F.C.C.; writing-original draft preparation, K.Y., T.R., S.A., and F.C.C.; writing-review and editing, K.Y. and T.R.; supervision, T.R. All authors have read and agreed to the published version of the manuscript.

Funding: No external funding was received for this research.

Acknowledgments: We would like to take this opportunity to acknowledge the time and effort devoted by reviewers to improving the quality of this manuscript.

Conflicts of Interest: The authors declare no conflict of interest.

\section{Appendix A}

Sample Questions of Background Knowledge Test (Cartoon) (Multiple-Choice Task)

Q1. "It is the type of painting that exaggerates the topics it deals with to be funny or sarcastic." Which of the following concepts is related to this definition?
A) Poster
B) Porte
C) Table
D) Cartoon

Q2. It is the transfer of emotions, thoughts, and information between individuals. Which of the following concepts is related to this definition?
A) Communication
B) Cartoon
C) Picture
D) Literature

Q3. Which of the following cannot be used for cartoons?
A) Cartoons are used to make social and political criticism.
B) Cartoons are one of the important ways to communicate.
C) Cartoons are also used to entertain people and make them think.
D) Cartoons are one of the least used ways of communication. 
Q4. Which of the following is not about the process of communicating?

A) There is a source and buyer in the communication process

B) Gestures are used in communication.

C) Communication is a group activity.

D) Many techniques are used in communication other than written language.

\section{Appendix B}

Sample Items of Literal Reading Comprehension Test (Cartoon) (Sentence Verification Technique Task)

\begin{tabular}{|c|c|c|}
\hline $\begin{array}{c}\text { The cartoon presents less interesting and weaker } \\
\text { messages when compared to other art branches. }\end{array}$ & Correct & \\
\hline $\begin{array}{c}\text { It seems possible that the messages created by } \\
\text { cartoonists would reach the next generations. }\end{array}$ & & \\
\hline $\begin{array}{c}\text { Cartoonists can find opportunities to communicate } \\
\text { with people with their drawings. }\end{array}$ & & \\
\hline
\end{tabular}

\section{Appendix C}

Sample Items of Inferential Reading Comprehension Test (Cartoon) (Inference Verification Technique Task)

\begin{tabular}{|l|l|l|}
\hline $\begin{array}{l}\text { The fact that animated films are watched by millions of people } \\
\text { all over the world shows how important the messages given } \\
\text { through the cartoon/drawing are in the communication process. }\end{array}$ & & Incorrect \\
\hline $\begin{array}{l}\text { Cartoon forms a common language for communication } \\
\text { between people. Therefore, people from different nationalities can } \\
\text { easily understand each other through cartoons. }\end{array}$ & & \\
\hline $\begin{array}{l}\text { Cartoons are used only without writing in the process of } \\
\text { creating effective communication. }\end{array}$ & & \\
\hline
\end{tabular}

\section{References}

1. Reed, D.; Lynn, D. The effects of an inference-making strategy taught with and without goal setting. Learn. Disabil. Q. 2016, 39, 133-145. [CrossRef]

2. Strømsø, H.I.; Bråten, I.; Samuelstuen, M.S. Dimensions of topic-specific epistemological beliefs as predictors of multiple text understanding. Learn. Instr. 2008, 18, 513-527. [CrossRef]

3. Ulu, M. A structural Equation model to explain the effect of fluent reading, literal comprehension and inferential comprehension levels of elementary school 4th grade students on success in problem solving. Educ. Sci. 2016, 41, 93-117. [CrossRef]

4. Akyol, H. Turkish Language Arts Teaching Methods; Kok Publishing: Ankara, Turkey, 2006.

5. Dorn, J.; Soffos, C. Teaching for Deep Comprehension; Stenhouse Publisher: Portland, OR, USA, 2005.

6. Grabe, W.; Stoller, F.L. Teaching and Researching Reading; Pearson Education Limited: Great Britain, UK, 2011.

7. LaRusso, M.; Kim, H.Y.; Selman, R.; Uccelli, P.; Dawson, T.; Jones, S.; Donovan, S.; Snow, K. Contributions of academic language, perspective taking, and complex reasoning to deep reading comprehension. J. Res. Educ. Eff. 2016, 9, 201-222. [CrossRef]

8. Hempenstall, J. Read About It: Scientific Evidence for Effective Teaching of Reading; (The Center for Independent Studies Research Report 11); Author: Canberra, Australia, 2016.

9. Kim, Y.S.; Wagner, R.; Lopez, D. Developmental relations between reading fluency and reading comprehension: A longitudinal study from grade one to two. J. Exp. Child Psychol. 2012, 113, 93-111. [CrossRef]

10. Mariotti, A.P. 5 Sustaining students' reading comprehension. Kappa Delta Rec. 2010, 46, 87-89. [CrossRef]

11. Nassaji, H. Schema theory and knowledge-based processes in second language reading comprehension: A need for alternative perspectives. Lang. Learn. 2002, 52, 439-481. [CrossRef] 
12. Young, C.; Nageldinger, J. Considering the context and texts for fluency: Performance, readers theater, and poetry. Int. Electron. J. Elem. Educ. 2014, 7, 47-56.

13. Caldwell, J.S. Reading Assessment: A Primer for Teachers and Coaches; The Guilford Press: New York, NY, USA, 2008.

14. Dickens, R.H.; Meisinger, E.B. Examining the effects of skill level and reading modality on reading comprehension. Read. Psychol. 2016, 37, 318-337. [CrossRef]

15. Kaya, D.; Yildirim, K. Evaluation of fourth grade students' reading fluency skills in regard to deep and literal comprehension levels. J. Mother Tongue Educ. 2016, 4, 416-430.

16. Klauda, S.L.; Guthrie, J.T. Relationships of three components of reading fluency to reading comprehension. J. Educ. Psychol. 2008, 100, 310-321. [CrossRef]

17. Yildirim, K.; Rasinski, T.; Ates, S.; Fitzgerald, S.; Zimmerman, B.; Yildiz, M. The relationship between reading fluency and vocabulary in fifth grade Turkish students. Lit. Res. Instr. 2014, 53, 72-89. [CrossRef]

18. Rasinski, T.V.; Reutzel, D.R.; Chard, D.; Linan-Thompson, S. Reading fluency. In Handbook of Reading Research; Kamil, M.L., Pearson, P.D., Moje, E.B., Afflerbach, P.P., Eds.; Routledge: Philadelphia, PA, USA, 2011; pp. 286-319.

19. Wang, Y.H. Reading strategy use and comprehension performance of more successful and less successful readers: A think-aloud study. Educ. Sci. Theory Pract. 2016, 16, 1789-1813.

20. Moreillon, J. Collaborative Strategies for Teaching Reading Comprehension; American Library Association: Chicago, IL, USA, 2007.

21. Liebfreund, M.D.; Conradi, K. Component skills affecting elementary students' informational text comprehension. Read Write 2016, 29, 1141-1160. [CrossRef]

22. Burin, D.I.; Barreyro, J.P.; Saux, G.; Irrazábal, N.C. Navigation and comprehension of digital expository texts: Hypertext structure, previous domain knowledge, and working memory capacity. Electron. J. Res. Educ. Psychol. 2015, 13, 529-550. [CrossRef]

23. Ates, A. Metacognitive awareness levels of reading strategies of university students (Inonu university case). Int. J. Turk. Lit. Cult. Educ. 2013, 4, 258-273.

24. Afflerbach, P.; Pearson, P.D.; Paris, S.G. Clarifying differences between reading skills and reading strategies. Read. Teach. 2008, 61, 364-373. [CrossRef]

25. Best, R.M.; Rowe, M.; Ozuru, Y.; McNamara, D.S. Deep-level comprehension of science texts the role of the reader and the text. Top. Lang. Disord. 2005, 25, 65-83. [CrossRef]

26. Pittman, P.; Honchell, B. Literature discussion: Encouraging reading interest and comprehension in struggling middle school readers. J. Lang. Lit. Educ. 2014, 10, 118-133.

27. Boardman, A.G.; Buckley, P.; Vaughn, S.; Roberts, G.; Scornavacco, K.; Klingner, J.K. Relationship between implementation of collaborative strategic reading and student outcomes for adolescents with disabilities. J. Learn. Disabil. 2016, 49, 644-657. [CrossRef]

28. Cer, E.; Sahin, E. Improving reading comprehension skills with children's books through metacognitive strategy: The Turkish Context. J. Educ. Train. Stud. 2016, 4, 109-119.

29. Hitchcock, J.; Dimino, J.; Kurki, A.; Wilkins, C.; Gerstein, R. The Impact of Collaborative Strategic Reading on The Reading Comprehension of Grade 5 Students in Linguistically Diverse Schools; (Final Report); U.S. Department of Education, Institute of Education Sciences: Washington, DC, USA, 2011.

30. Radcliffe, B.J. Reading Vitals (Visualizing, Interacting, and Talking While Applying Literacy Strategies) and Seventh-Grade Students' Reading Comprehension. Ph.D. Thesis, Florida State University, Tallahassee, FL, USA, 2010.

31. Shen, Y. An exploration of schema theory in intensive reading. Engl. Lang. Teach. 2008, 2, 104-107. [CrossRef]

32. Yildirim, K. Fluency-based skills of reading and their relations with reading comprehension in Turkish elementary school children. Int. J. Acad. Res. 2013, 5, 134-139. [CrossRef]

33. Akyel, A.; Ercetin, G. Hypermedia reading strategies employed by advanced learners of English. System 2009, 37, 136-152. [CrossRef]

34. Ates, S.; Yildirim, K. Elementary school classroom teachers' reading practices: Strategy instruction and comprehension. Elem. Educ. Online 2014, 13, 235-257.

35. Beydogan, $\mathrm{O}$. Students' level of using reading-comprehension strategies in relation to their proficiencies in reading fluently. Educ. Sci. 2012, 37, 3-13.

36. Rasinski, T.V. Creating fluent readers. Educ. Leadersh. 2004, 61, 46-51. 
37. Yildiz, M.; Yildirim, K.; Ates, S.; Cetinkaya, C. An evaluation of the oral reading fluency of 4th graders with respect to prosodic characteristic. Int. J. Hum. Sci. 2009, 6, 353-360.

38. Paige, D.D.; Rasinski, T.V.; Magpuri-Lavell, T. Is fluent, expressive reading important for high school readers? J. Adolesc. Adult Lit. 2012, 56, 67-76. [CrossRef]

39. Rasinski, T.; Homan, S.; Biggs, M. Teaching reading fluency to struggling readers: Method, materials, and evidence. Read. Writ. Q. 2009, 25, 192-204. [CrossRef]

40. Kozminsky, E.; Kozminsky, L. How do general knowledge and reading strategies ability relate to reading comprehension of high school students at different educational levels? J. Res. Read. 2001, 24, 187-204. [CrossRef]

41. Brand-Gruwel, S.; Aarnoutse, C.; Van Den Bos, K.P. Improving text comprehension strategies in reading and listening settings. Learn. Instr. 1998, 8, 63-81. [CrossRef]

42. Cromley, J.G.; Azevedo, R. Testing and refining the direct and inferential mediation model of reading comprehension. J. Educ. Psychol. 2007, 99, 311-325. [CrossRef]

43. Seipel, B.; Carlson, S.E.; Clinton, V.E. When do comprehender groups differ? A moment-by-moment analysis of think-aloud protocols of good and poor comprehenders. Read. Psychol. 2017, 38, 39-70. [CrossRef]

44. Ulper, H. Reading process: Cognitive functions, comprehension and reading strategies. Cito Educ. Theory Pract. 2010, 1, 32-44.

45. Rasinski, T.V. Assessing Reading Fluency; Pacific Resources for Education and Learning: Honolulu, HI, USA, 2004.

46. Bollen, K.A. Structural Equations with Latent Variables; Wiley: New York, NY, USA, 1989.

47. Kline, R.B. Principles and Practice of Structural Equation Modeling; Guilford Publications: New York, NY, USA, 2015.

48. Duke, N.K.; Pearson, P.D. Effective practices for developing reading comprehension. In What Research Has to Say About Reading Instruction, 3rd ed.; Farstrup, A.E., Samuels, S.J., Eds.; International Reading Association: Newark, NJ, USA, 2002; pp. 205-242.

49. Medine, J.M. Through literacy to fluency: Reading in the religious studies classroom. Teach. Theol. Relig. 2016, 19, 359-377. [CrossRef]

50. Royer, J.M.; Carlo, M.S.; Dufresne, R.; Mestre, J. The assessment of levels of domain expertise while reading. Cogn. Instr. 1996, 14, 373-408. [CrossRef]

51. Kuhn, M.R.; Schwanenflugel, P.J. (Eds.) Fluency in the Classroom; The Guilford Press: New York, NY, USA, 2008.

52. Pey, C.H.; Min, H.L.; Wah, L.L. Relationship between oral reading fluency and reading comprehension among ESL students. J. Lang. Stud. 2014, 14, 19-32.

53. Pretorius, E.J.; Spaull, N. Exploring relationships between oral reading fluency and reading comprehension amongst English second language readers in South Africa. Read Writ 2016, 29, 1449-1471. [CrossRef]

54. Veenendaal, N.J.; Groen, M.A.; Verhoeven, L. The contribution of segmental and suprasegmental phonology to reading comprehension. Read. Res. Q. 2016, 51, 55-66.

55. Reading Study Group (RAND). Reading for Understanding: Toward an RED Program in Reading Comprehension; RAND Corporation: Washington, DC, USA, 2002.

(C) 2020 by the authors. Licensee MDPI, Basel, Switzerland. This article is an open access article distributed under the terms and conditions of the Creative Commons Attribution (CC BY) license (http://creativecommons.org/licenses/by/4.0/). 